\title{
Effect of leucine on intestinal absorption of tryptophan in rats
}

\author{
BY CHISAE UMEZAWA, YUKO MAEDA, KANJI HABA, \\ MARIKO SHIN AND KEIJI SANO \\ School of Pharmacy, Kobe-Gakuin University, Nishi-ku, Kobe 673, Japan
}

(Received 17 May 1985 - Accepted 24 June 1985)

1. To elucidate the causal relation between leucine and the lowering of hepatic NAD content of rats fed on a leucine-excessive diet (Yamada et al. 1979), the effect of leucine on intestinal absorption of tryptophan was investigated.

2. Co-administration of $\left[{ }^{3} \mathrm{H}\right]$ tryptophan and leucine, with leucine at ten times the level of tryptophan, delayed absorption of $\mathrm{L}$-[side chain $\left.2,3-{ }^{3} \mathrm{H}\right]$ tryptophan from the digestive tract and incorporation of $\left[{ }^{3} \mathrm{H}\right]$ tryptophan into portal blood, the liver and a protein fraction of the liver. After $120 \mathrm{~min}$, more than $95 \%$ of tryptophan was absorbed whether $\left[{ }^{3} \mathrm{H}\right]$ tryptophan was administered with or without leucine.

3. Co-administration of a mixture of ten essential amino acids, in proportions simulating casein, with $\left[{ }^{\mathrm{a}} \mathrm{H}\right]$ tryptophan markedly delayed absorption of tryptophan from the digestive tract. The addition of supplementary leucine to the amino acid mixture, however, caused no further delay.

4. In rats prefed a leucine-excessive diet for 1 week $\left[{ }^{3} \mathrm{H}\right]$ tryptophan was absorbed at the same rate as in rats fed on a control diet.

5. The results indicate that competition between tryptophan and leucine for intestinal absorption did not cause lowering of hepatic NAD.

A dietary excess of leucine is known to cause a significant reduction in the hepatic NAD content in rats (Yamada et al. 1979; Sakakibara et al. 1982; Magboul \& Bender, 1983). It has been demonstrated that NAD biosynthesis from tryptophan in isolated rat liver cells is inhibited by $\alpha$-ketoisocaproic acid, the deaminated derivative of leucine, and ketone bodies (Yamada et al. 1983a), and that $\alpha$-ketoisocaproic acid in plasma and ketone bodies in the liver doubled after $7 \mathrm{~d}$ of feeding a leucine-excessive diet (Yamada et al. 1983b).

On the other hand, by conducting a short-term (5-7.5 min) study, Sakakibara et al. (1982) suggested that the decrease in hepatic NAD content of rats fed on a diet supplemented with excessive leucine was due to competitive inhibition of intestinal absorption of tryptophan by leucine. The amino acids must be absorbed from the digestive tract before their metabolic utilization in the liver and, therefore, how competition between tryptophan and leucine for intestinal absorption affects later metabolism of tryptophan must be determined.

In the present report, the authors have studied the effect of excess dietary leucine on tryptophan metabolism by determining not only the amount of $\mathrm{L}-\left[2,3-{ }^{3} \mathrm{H}\right]$ tryptophan transported to the portal vein, as Sakakibara et al. (1982) did, but also the amount of $\left[{ }^{3} \mathrm{H}\right]$ tryptophan remaining in the digestive tract and that incorporated into protein fractions of the liver and the kidney after oral administration of $\left[{ }^{3} \mathrm{H}\right]$ tryptophan to rats with or without leucine.

\section{MATERIALS AND METHODS}

\section{Chemicals}

L-[side chain-2,3- ${ }^{3} \mathrm{H}$ ]Tryptophan $(40-60 \mathrm{Ci} / \mathrm{mmol})$ was purchased from Commissariat a L'energie Atomique, France, and purified before use by high-performance liquid chromatography using a Twincle pump with a UVIDEC-100 III monitor, a VL-611 injector and a Finepak SIL C18-5 column $(4.6 \times 25 \mathrm{~mm})$ supplied by Japan Spectroscopic Co., Ltd. Methanol $(5 \%)$ was used as the mobile phase. Soluene-350 and ACS II were obtained 
from Packard Instrument Co. and Amersham International respectively. L-Tryptophan, L-leucine and other L-amino acids were purchased from either Nakarai Chemicals or Wako Pure Chemical Industries, Japan.

\section{Animals}

Male Sprague-Dawley rats (specific pathogen free; 4 weeks old) were purchased from Shizuoka Agricultural Cooperative Association for Laboratory Animals, Japan. All rats were prefed on either a commercial stock diet (MF diet; Oriental Yeast Co., Japan) or a $200 \mathrm{~g}$ casein $/ \mathrm{kg}$ diet supplemented with $50 \mathrm{~g}$ leucine $/ \mathrm{kg}$ (Yamada et al. 1979) ad lib. for 1 week.

\section{Experimental procedure}

After an overnight fast, a solution of $10 \mu$ mol tryptophan in $1 \mathrm{ml}$ physiological saline $(9 \mathrm{~g}$ sodium chloride/l) containing $2-2 \cdot 5 \mu \mathrm{Ci} \mathrm{L}-\left[2,3-{ }^{3} \mathrm{H}\right]$ tryptophan was given by stomach tube with or without $100 \mu \mathrm{mol}$ leucine. A similar procedure was followed using an essential amino acid mixture simulating casein. The mixture, contributing the following amounts $(\mu \mathrm{mol} / 2 \mathrm{ml}$ ): tryptophan $10 \cdot 0$, lysine $79 \cdot 6$, arginine $40 \cdot 8$, histidine $33 \cdot 5$, phenylalanine $47 \cdot 3$, isoleucine $72 \cdot 5$, valine $91 \cdot 5$, methionine $30 \cdot 2$, threonine $52 \cdot 1$, leucine 111 , and containing $2 \mu \mathrm{Ci} \mathrm{L}-\left[2,3-{ }^{3} \mathrm{H}\right]$ tryptophan, was given as a solution by stomach tube with or without $140 \mu \mathrm{mol}$ leucine. Under Nembutal anaesthesia, the animal was laparotomized, portal blood was collected and the liver, the kidney and the digestive tract were quickly removed.

\section{Preparation of samples}

Blood. The blood was deproteinized with perchloric acid (the final concentration was $0.5 \mathrm{M}$ ) and a portion of the resulting supernatant fraction was dissolved in 10 vol. ACS II for measurement of radioactivity. No measurable radioactivity was found in the $\mathrm{HClO}_{4}$ precipitable (protein) fraction.

Liver. A portion of the liver was homogenized with 3 vol. water by Polytron (Type PT 10/35; Kinematica, Switzerland). A portion of the homogenate was solubilized with Soluene and then dissolved in ACS II for radioactivity measurement (A). The homogenate was deproteinized with $\mathrm{HClO}_{4}$ (the final concentration was $0.5 \mathrm{M}$ ) and a portion of the resulting supernatant fraction was dissolved in ACS II for radioactivity measurement (B). The difference between A and B corresponding to the same amount of the liver was defined as the radioactivity of tryptophan incorporated into an acid-insoluble fraction. The value thus obtained coincided well with the radioactivity of a protein fraction actually determined by the following method. An acid-insoluble fraction, which was obtained by either centrifugation or filtration of the homogenate deproteinized with trichloroacetic acid (TCA; final concentration was $100 \mathrm{~g} / \mathrm{l})$, was heated with TCA $(100 \mathrm{~g} / \mathrm{l})$ for $30 \mathrm{~min}$ at $90^{\circ}$ for nucleic acid extraction and washed with TCA $(100 \mathrm{~g} / \mathrm{l})$ and ethanol successively. The resultant protein residue was solubilized with Soluene and radioactivity was measured after dissolving the residue in ACS II. Little radioactivity was incorporated into the nucleic acid fraction.

Kidney. The kidney was treated similarly to the liver.

Digestive tract. The digestive tract was divided into four portions, namely the stomach, the upper half of the small intestine, the lower half of the small intestine and the caecum plus the large intestine. Each portion of the digestive tract plus its content was homogenized with $0.8 \mathrm{M}-\mathrm{HClO}_{4}$ by Polytron. Denatured protein was removed by centrifugation and a portion of the supernatant fraction was used for measuring radioactivity in ACS II. The protein fraction contained little radioactivity. 


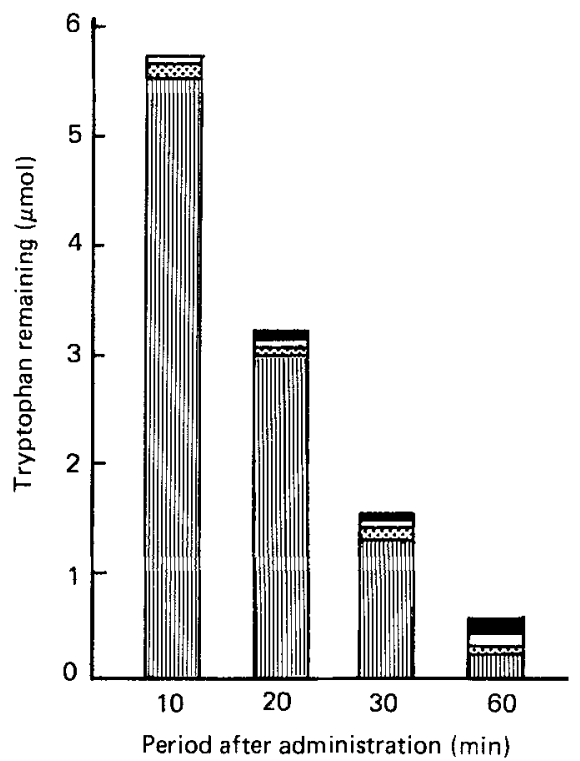

Fig. 1. Tryptophan remaining in various regions of the digestive tract after oral administration of $10 \mu \mathrm{mol}$ ${ }^{3} \mathrm{H}$-labelled tryptophan. ( $\square$ ), Stomach; (圈), upper small intestine; ( $\square$ ), lower small intestine; ( $\square$ ), caecum + large intestine.

\section{RESULTS}

The time-course of tryptophan absorption from the digestive tract was first investigated in rats administered only tryptophan. Fig. 1 shows the amount of tryptophan remaining unabsorbed in the digestive tract after oral administration of $10 \mu \mathrm{mol}$ tryptophan containing $2 \mu \mathrm{Ci} \mathrm{L-}\left[2,3-{ }^{3} \mathrm{H}\right]$ tryptophan. A major portion of tryptophan in the digestive tract remained in the stomach, which indicated that tryptophan was absorbed soon after being transferred to the upper part of the small intestine. After $60 \mathrm{~min}, 95 \%$ of the administered tryptophan was absorbed. Fig. 2 shows the incorporation of administered tryptophan into portal blood. Portal tryptophan reached its maximum after $30 \mathrm{~min}$ and decreased after 60 min when tryptophan was absorbed almost completely from the digestive tract (Fig. 1). Fig. 3 shows the amount of tryptophan incorporated into the liver. The total amount of tryptophan incorporated into the liver increased with time, the major proportion being incorporated into a protein fraction. Although the pattern of tryptophan incorporation into the kidney was similar to that into the liver, tryptophan incorporation into a protein fraction was rather low, corresponding to $50-70 \%$ of total tryptophan incorporated into the kidney (values not shown).

Figs. 4 and 5 show the absorption patterns of tryptophan in the animals given $\left[{ }^{3} \mathrm{H}\right]$ tryptophan and leucine, with leucine at ten times the level of tryptophan. As shown in Fig. 4, absorption of tryptophan from the digestive tract was delayed by $30 \mathrm{~min}$ compared with that found when only tryptophan was administered (cf. Fig. 1). Tryptophan remained mostly in the stomach and was absorbed almost completely by $120 \mathrm{~min}$. Although maximal incorporation of tryptophan into portal blood was attained after $60 \mathrm{~min}$ in the rats given tryptophan with leucine (Fig. 5) instead of $30 \mathrm{~min}$ in the rats given only tryptophan (Fig. 2), the maximal tryptophan level in portal blood was almost the same in both groups. As tryptophan was absorbed almost completely, even in the animals which had 


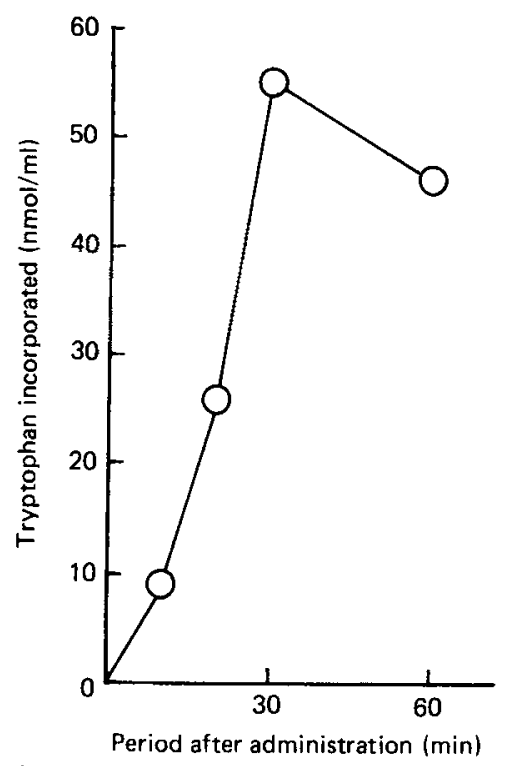

Fig. 2. Tryptophan incorporation into portal blood after oral administration of $10 \mu \mathrm{mol}{ }^{3} \mathrm{H}$-labelled tryptophan.

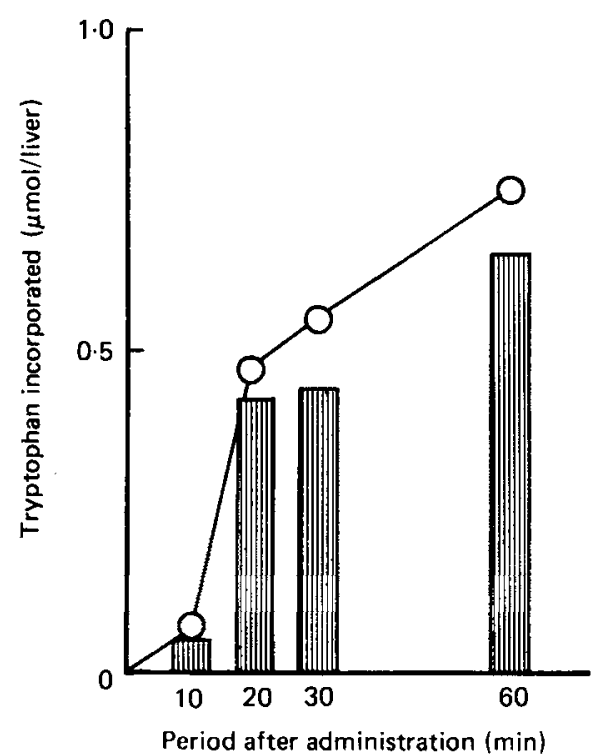

Fig. 3. Tryptophan incorporation into liver and hepatic protein after oral administration of $10 \mu \mathrm{mol}$ ${ }^{3} \mathrm{H}$-labelled tryptophan. (O), Total amount of tryptophan incorporated into liver; $(\square)$, amount of tryptophan incorporated into hepatic protein.

tryptophan with leucine administered, distribution of tryptophan was compared between two groups given $\left[{ }^{3} \mathrm{H}\right]$ tryptophan with or without excess leucine at 60 and $120 \mathrm{~min}$ after its oral administration (by these times over $80 \%$ of tryptophan had been absorbed in both groups; see Figs. 1 and 4). After 60 min, tryptophan remaining in the digestive tract was significantly higher in the group given tryptophan with leucine (Table 1). Tryptophan 


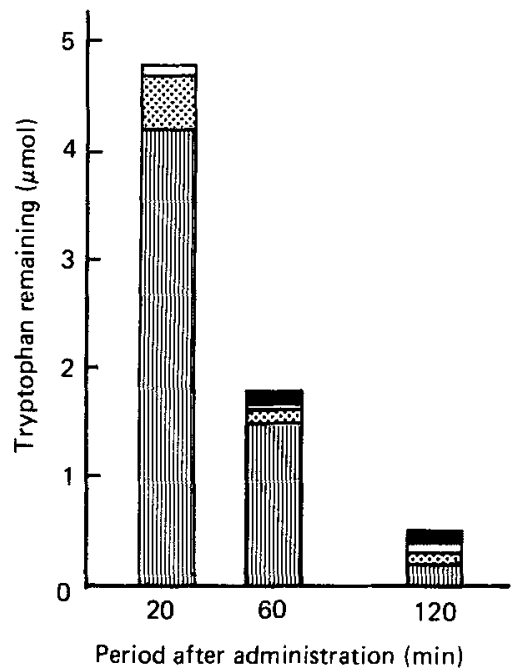

Fig. 4. Tryptophan remaining in various regions of the digestive tract after oral administration of $10 \mu \mathrm{mol}$ ${ }^{3} \mathrm{H}$-labelled tryptophan with $100 \mu \mathrm{mol}$ leucine. ( $\square$ ), Stomach; (圈), upper small intestine; ( $\square$ ), lower small intestine; (C), caecum + large intestine.

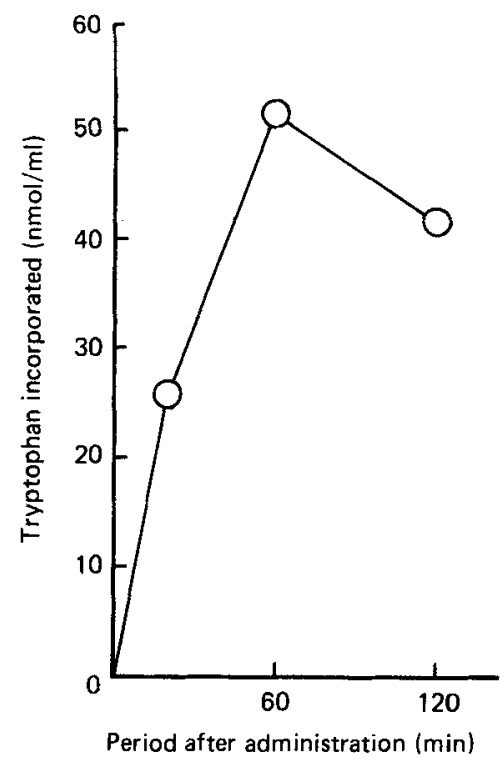

Fig. 5. Tryptophan incorporation into portal blood after oral administration of $10 \mu \mathrm{mol}^{3} \mathrm{H}$-labelled tryptophan with $100 \mu \mathrm{mol}$ leucine.

incorporated into portal blood and the liver after 60 min was not significantly different in the two groups. After $120 \mathrm{~min}$ no difference between the two groups was observed in the amount of tryptophan remaining in the digestive tract and that incorporated into portal blood and the liver.

In the following experiment, to bring the experimental conditions closer to that in the animals fed on a leucine-excessive diet, tryptophan was orally administered together with ten essential amino acids in proportions simulating casein (corresponding to $0.8 \mathrm{~g}$ of the 
Table 1. The effect of $100 \mu \mathrm{mol}$ leucine on intestinal absorption of $10 \mu \mathrm{mol}\left[{ }^{3} \mathrm{H}\right]$ tryptophan and incorporation of $\left[{ }^{3} H\right]$ tryptophan into portal blood and liver

(Mean values and standard deviations for three animals)

\begin{tabular}{|c|c|c|c|c|c|c|c|c|}
\hline \multirow{3}{*}{$\begin{array}{l}\text { Period after tryptophan } \\
\text { administration (min) ... }\end{array}$} & \multicolumn{4}{|c|}{$\left[{ }^{3} \mathrm{H}\right]$ Tryptophan } & \multicolumn{4}{|c|}{$\left[{ }^{3} \mathrm{H}\right]$ Tryptophan + leucine } \\
\hline & \multicolumn{2}{|c|}{60} & \multicolumn{2}{|c|}{120} & \multicolumn{2}{|c|}{60} & \multicolumn{2}{|c|}{120} \\
\hline & Mean & SD & Mean & $\mathrm{SD}$ & Mean & SD & Mean & SD \\
\hline $\begin{array}{l}\text { Tryptophan remaining } \\
\text { in digestive tract }(\mu \mathrm{mol})\end{array}$ & $0 \cdot 82$ & 0.08 & 0.48 & 0.08 & $1 \cdot 73^{*}$ & 0.55 & 0.50 & 0.08 \\
\hline \multicolumn{9}{|c|}{ Tryptophan incorporated into: } \\
\hline Portal blood $(\mathrm{nmol} / \mathrm{ml})$ & 56 & 12 & 39 & 7 & 52 & 6 & 42 & 7 \\
\hline Liver ( $\mu \mathrm{mol} /$ liver) & 0.52 & 0.09 & 0.41 & 0.05 & 0.51 & 0.08 & 0.44 & 0.05 \\
\hline Hepatic protein $(\%)$ & $89 \cdot 4$ & $2 \cdot 3$ & $79 \cdot 6$ & $3 \cdot 0$ & $86 \cdot 7$ & $5 \cdot 6$ & $84 \cdot 0$ & $4 \cdot 0$ \\
\hline
\end{tabular}

Mean value was significantly different from the control group given $\left[{ }^{3} \mathrm{H}\right]$ tryptophan alone (Student's $t$ test): $* P<0.05$.

Table 2. The effect of $140 \mu \mathrm{mol}$ leucine on intestinal absorption of $10 \mu \mathrm{mol}\left[{ }^{3} \mathrm{H}\right]$ tryptophan administered with an essential amino acid mixture simulating those of casein, and incorporation of $\left[{ }^{3} \mathrm{H}\right]$ tryptophan into portal blood and liver

(Mean values and standard deviations for three animals)

Period after tryptophan administration (min) ...
[3]Tryptophan $+$ essential amino acid mixture $+$ leucine amino acid mixture

\begin{tabular}{|c|c|c|c|c|c|c|c|}
\hline \multicolumn{2}{|c|}{60} & \multicolumn{2}{|c|}{120} & \multicolumn{2}{|c|}{60} & \multicolumn{2}{|c|}{120} \\
\hline Mean & SD & Mean & SD & Mean & SD & Mean & SD \\
\hline $3 \cdot 55$ & 0.96 & $1 \cdot 10$ & $0 \cdot 10$ & $2 \cdot 58$ & 0.88 & 0.99 & 0.17 \\
\hline 82 & 13 & 61 & 10 & 112 & 24 & 61 & 6 \\
\hline 1.42 & $0 \cdot 12$ & 1.59 & 0.14 & 1.55 & 0.03 & $1 \cdot 57$ & 0.06 \\
\hline 90.9 & $2 \cdot 4$ & $90 \cdot 6$ & $2 \cdot 3$ & $93 \cdot 7$ & 0.7 & 93.6 & $4 \cdot 5$ \\
\hline
\end{tabular}

$200 \mathrm{~g}$ casein $/ \mathrm{kg} \mathrm{diet)}$ with or without supplementary leucine. The proportion of leucine added was equivalent to that in the $200 \mathrm{~g}$ casein $/ \mathrm{kg}$ diet supplemented with $25 \mathrm{~g}$ leucine $/ \mathrm{kg}$ which, when fed, was shown to cause significant lowering of hepatic NAD level after 1 week (Sakakibara et al. 1982). Tryptophan remaining in the digestive tract of the animals which had $\left[{ }^{3} \mathrm{H}\right]$ tryptophan with a mixture of essential amino acids administered was higher than that found in the digestive tract of the animals which had $\left[{ }^{3} \mathrm{H}\right]$ tryptophan with leucine administered (cf. Tables 1 and 2), which indicated that the presence of various amino acids further delayed intestinal absorption of tryptophan. Simultaneous administration of excessive leucine, however, did not cause any significant difference in the amounts of 
Table 3. The effect of prefeeding a $200 \mathrm{~g}$ casein $/ \mathrm{kg}$ diet supplemented with $50 \mathrm{~g}$ leucine $/ \mathrm{kg}$ on intestinal absorption of $10 \mu \mathrm{mol}\left[{ }^{3} \mathrm{H}\right]$ tryptophan and incorporation of $\left[{ }^{3} \mathrm{H}\right]$ tryptophan into portal blood and liver

(Mean values and standard deviations for four animals)

\begin{tabular}{|c|c|c|c|c|c|c|c|c|}
\hline \multirow{3}{*}{$\begin{array}{l}\text { Diet... } \\
\text { Period after tryptophan } \\
\text { administration (min)... }\end{array}$} & \multicolumn{4}{|c|}{$200 \mathrm{~g}$ Casein $/ \mathrm{kg}$ diet } & \multicolumn{4}{|c|}{$\begin{array}{l}200 \mathrm{~g} \text { Casein } / \mathrm{kg} \text { diet } \\
+50 \mathrm{~g} \text { leucine } / \mathrm{kg} \text { diet }\end{array}$} \\
\hline & \multicolumn{2}{|c|}{60} & \multicolumn{2}{|c|}{120} & \multicolumn{2}{|c|}{60} & \multicolumn{2}{|c|}{120} \\
\hline & Mean & SD & Mean & SD & Mean & SD & Mean & so \\
\hline Tryptophan remaining in digestive tract $(\mu \mathrm{mol})$ & 0.95 & $0 \cdot 37$ & 0.40 & 0.09 & 0.82 & $0 \cdot 19$ & 0.39 & $0 \cdot 08$ \\
\hline \multicolumn{9}{|l|}{ Tryptophan incorporated into: } \\
\hline Portal blood $(\mathrm{nmol} / \mathrm{ml})$ & 62 & 10 & 44 & 4 & 64 & 9 & 47 & 8 \\
\hline Liver ( $\mu \mathrm{mol} /$ liver) & 0.55 & 0.09 & 0.57 & 0.06 & 0.56 & 0.03 & 0.48 & $0 \cdot 10$ \\
\hline Hepatic protein $(\%)$ & $90 \cdot 0$ & $1 \cdot 3$ & $86 \cdot 5$ & $2 \cdot 3$ & $86 \cdot 5$ & $3 \cdot 3$ & $80 \cdot 6$ & 5.4 \\
\hline
\end{tabular}

tryptophan remaining in the digestive tract and those incorporated into portal blood, the liver and the hepatic protein fraction (Table 2). Little tryptophan was found in the lower part of the intestine of either group (values not shown). The amount of tryptophan incorporated into the hepatic protein fraction was three times that found in the animals given tryptophan alone or tryptophan with leucine (cf. Tables 1 and 2).

There is a possibility that feeding a leucine-excessive diet for a certain period may lead to changes in transport systems of amino acids. Therefore, after 1 week of feeding either a $200 \mathrm{~g}$ casein $/ \mathrm{kg}$ diet or a $200 \mathrm{~g}$ casein $/ \mathrm{kg}$ diet supplemented with $50 \mathrm{~g}$ leucine $/ \mathrm{kg}$, distribution of orally-administered tryptophan was similarly tested in the presence of ten times its level of leucine. As shown in Table 3, prefeeding a leucine-excessive diet did not cause any change in $\left[{ }^{3} \mathrm{H}\right]$ tryptophan uptake and no differences were observed between the two feeding groups in the amount of tryptophan remaining in the digestive tract and that incorporated into portal blood and the liver.

\section{DISCUSSION}

The authors reported previously that the hepatic NAD level was lowered significantly in the rats fed on a leucine-supplemented diet (Yamada et al. 1979). Sakakibara et al. (1982) observed a similar NAD-lowering effect with excess dietary leucine, for which they presumed that inhibition of tryptophan absorption from the digestive tract by leucine was responsible. If their presumption is correct, tryptophan incorporation into protein, a main metabolic pathway of tryptophan, would also be greatly affected. In the present report, therefore, the amount of tryptophan remaining in the digestive tract and amounts of tryptophan incorporated into portal blood and protein fractions of the liver and the kidney were examined simultaneously in the animals to which either $\left[2,3-{ }^{3} \mathrm{H}\right]$ tryptophan alone or an amino acid mixture containing $\left[2,3-{ }^{3} \mathrm{H}\right]$ tryptophan with or without supplementary leucine was administered orally. The effect of leucine on intestinal absorption of tryptophan was also examined in the animals prefed a $200 \mathrm{~g}$ casein $/ \mathrm{kg}$ diet with or without leucine supplementation.

As can be seen from Table 1, no differences were observed in the values determined 120 min after oral administration of either tryptophan alone or tryptophan together with leucine. Little tryptophan was detected in the lower part of the small intestine (values not 
shown). Tryptophan remaining in the digestive tract was no more than $5 \%$ of the administered dose in both groups. These findings indicate that tryptophan was absorbed almost completely, regardless of the presence of leucine, although absorption of tryptophan was rather delayed in the presence of leucine.

It was demonstrated by Sakakibara et al. (1982) that uptake of tryptophan into isolated jejunal segments during a short time-period of $7.5 \mathrm{~min}$ was markedly inhibited by leucine, isoleucine, valine, methionine and phenylalanine, transport of which is known to be mediated by system $\mathrm{L}$ in various mammalian cells (Shotwell \& Oxender, 1983; Shotwell et al. 1983; Christensen, 1984a,b). It is not clear at this point of time how many specific transport systems for amino acids exist in the intestinal mucosal tissues and how they are regulated. However, the finding by Sakakibara et al. (1982) that accumulation of tryptophan in isolated jejunal segments was inhibited by leucine, valine, isoleucine, phenylalanine and methionine, but not by lysine, aspartate, alanine or glycine, strongly suggests that tryptophan is transported by the so-called system $\mathbf{L}$ in rat jejunum.

In the present study, intestinal absorption of tryptophan was delayed when tryptophan was administered orally with ten times its level of leucine (Table 1). The absorptive area of the digestive tract is immense. Therefore, even if leucine competes with tryptophan for the common transport carrier locally, transport of tryptophan is supposed to be facilitated in the lower part of jejunum, where competing leucine molecules are expected to decrease. Actually all the orally-administered tryptophan was absorbed and not transferred to the lower part of the small intestine.

It is known that uptake of amino acids by system $\mathrm{L}$ is trans-stimulated by intracellular substrates of this system. According to Tannous et al. (1966), the concentration of leucine in the liver reached $1 \mathrm{~mm}$ after feeding rats with a $200 \mathrm{~g}$ casein $/ \mathrm{kg}$ diet supplemented with $50 \mathrm{~g}$ leucine $/ \mathrm{kg}$ for $1 \mathrm{~d}$. Although leucine concentration in tissues, possibly in jejunal mucosa and the liver, of rats shown in Table 3 is also supposed to be raised, stimulation of intestinal absorption or tissue incorporation of $\left[{ }^{3} \mathrm{H}\right]$ tryptophan was not observed in the animals prefed on a leucine-excessive diet (Table 3).

A proposal by Sakakibara et al. (1982) that the decreased hepatic NAD content was due to the competitive inhibition of intestinal absorption of tryptophan by the high dietary leucine level is inconsistent with the finding by one of their co-workers that dietary excess of phenylalanine or methionine, which was found to inhibit tryptophan uptake by isolated rat jejunal segments in the same way as leucine, did not cause any decrease in the hepatic NAD content (Fujii, 1979).

In the present study, an amount of $\left[{ }^{3} \mathrm{H}\right]$ tryptophan eventually incorporated into the liver and hepatic protein fraction was not affected by the high level of leucine, indicating that the same amount of tryptophan was supplied to the liver whether tryptophan was given with or without leucine. Competition between leucine and tryptophan for intestinal absorption, therefore, may not be the cause of reduction of NAD content in rats fed on a leucine-supplemented diet.

\section{REFERENCES}

Christensen, H. N. (1984a). Biochimica et Biophysica Acta 779, 255-269.

Christensen, H. N. (1984b). Nutrition Review 42, 237-242.

Fujii, K. (1979). Osaka Ika Daigaku Zasshi 38, 32-52.

Magboul, B. I. \& Bender, D. A. (1983). British Journal of Nutrition 49, 321-329.

Sakakibara, S., Fujii, K., Nasu, S., Imai, H., Yamaguchi, K. \& Ueda, I. (1982). Journal of Nutrition 112, $1688-1695$.

Shotwell, M. A., Kilberg, M. S. \& Oxender, D. L. (1983). Biochimica et Biophysica Acta 737, $267-284$.

Shotwell, M. A. \& Oxender, D. L. (1983). Trends in Biochemical Science 8, 314-316.

Tannous, R. I., Rogers, Q. R. \& Harper, A. E. (1966). Archives of Biochemistry and Biophysics 113, $356-361$. 
Yamada, O., Shin, M., Sano, K. \& Umezawa, C. (1979). International Journal of Vitamin and Nutrition Research 49, 376-385.

Yamada, O., Shin, M., Sano, K. \& Umezawa, C. (1983a). International Journal of Vitamin and Nutrition Research 53, 184-191.

Yamada, O., Shin, M., Sano, K. \& Umezawa, C. (1983b). International Journal of Vitamin and Nutrition Research 53, 192-198. 